Daniel Brandhorst ${ }^{1,4}$, Heide Brandhorst, ${ }^{1,4}$ Vidya Maataoui, ${ }^{2}$ Adel Maataoui, ${ }^{3}$ Paul Johnson ${ }^{1}$

\title{
Anti-caspase-3 preconditioning increases proinsulin secretion and deteriorates posttransplant function of isolated human islets
}

${ }^{1}$ Nuffield Department of Surgical Sciences, Oxford Centre for Islet Transplantation, University of Oxford, Oxford, United Kingdom; '2St. Anna Hospital, Wuppertal, Germany; ${ }^{3}$ Institute for Diagnostic and Interventional Radiology, Johan Wolfgang von Goethe University, Frankfurt am Main, Germany

${ }^{4}$ The first two authors contributed equally to this manuscript.

\section{Address for correspondence:}

Daniel Brandhorst, Nuffield Department of Surgical Sciences, Oxford Center for Diabetes, Endocrinology and Metabolism, University of Oxford, Churchill Drive, Oxford OX3 7LJ, United Kingdom; Phone: +44-1865-8-57252, Fax: +44-1865-8-57299; E-mail: Daniel.Brandhorst@nds.ox.ac.uk

\section{Abstract}

Human islet isolation is associated with adverse conditions inducing apoptosis and necrosis. The aim of the present study was to assess whether antiapoptotic preconditioning can improve in vitro and posttransplant function of isolated human islets.

A dose-finding study demonstrated that $200 \mu \mathrm{mol} / \mathrm{L}$ of the caspase-3 inhibitor Ac-DEVD-CMK was most efficient to reduce the expression of activated caspase- 3 in isolated human islets exposed to severe heat shock. Ac-DEVD-CMK-pretreated or sham-treated islets were transplanted into immunocompetent or immunodeficient diabetic mice and subjected to static glucose incubation to measure insulin and proinsulin secretion.

Antiapoptotic pretreatment significantly deteriorated graft function resulting in elevated nonfasting serum glucose when compared to sham-treated islets transplanted into diabetic nude mice ( $p<$ $0.01)$ and into immunocompetent mice $(p<0.05)$. Ac-DEVD-CMK pretreatment did not significantly change basal and glucose-stimulated insulin release compared to sham-treated human islets but increased the proinsulin release at high glucose concentrations $(20 \mathrm{mM})$ thus reducing the insulinto-proinsulin ratio in preconditioned islets $(p<0.05)$.

This study demonstrates that the caspase-3 inhibitor Ac-DEVD-CMK interferes with proinsulin conversion in preconditioned islets reducing their potency to cure diabetic mice. The mechanism behind this phenomenon is unclear so far but may be related to the ketone CMK linked to the AcDEVD molecule. Further studies are required to identify biocompatible caspase inhibitors suitable for islet preconditioning. 
Keywords: Human islet transplantation, apoptosis, caspase-3 inhibitors.

\section{Introduction}

Islet transplantation has been established as a significant treatment for patients suffering from lifethreatening hypoglycemic episodes (1) and has now reached equivalent function rates when compared to pancreas transplantation alone $(2,3)$. Nevertheless, the broad application of this treatment on diabetic patients is limited with respect to the percentage of islet preparations that have the potency to induce long-term insulin independence in recipients of islet allografts $(4,5)$.

The low efficiency of islet transplantation is mainly related to external variables such as ischemia (6) and immediate immune reactions in the recipients (7) but may also be explained by the intrinsic principle of enzymatic islet isolation. This process essentially involves the extraction of islets from their natural environment. After release from the acinar tissue islets are exposed to numerous insults during subsequent steps of islet production. Many of those factors are associated with the induction of apoptosis including removal of islets from the extracellular matrix $(8,9)$, use of hyperosmolaric media $(10,11)$, and incubation in a highly artificial and hypoxic environment during pretransplant culture $(12,13)$.

We previously demonstrated that islets preconditioning with the caspase-3 inhibitor $\mathrm{N}$-acetylDEVD-chloromethyl ketone (Ac-DEVD-CMK) increases islet posttransplant survival when determined as recovery of porcine and human insulin after transplantation in nondiabetic mice (14). The aim of the present study was therefore to investigate the potency of Ac-DEVD-CMK to improve the functional capacity of human islets transplanted into diabetic immunodeficient or immunocompetent mice. In addition, we assessed the impact of different caspase inhibitors on glucose-stimulated insulin and proinsulin secretion.

\section{Materials and methods}

All animal studies were approved by local ethics committees.

Islet isolation

Human islets were isolated from human multiorgan donors $(n=16)$ as previously described (15). Purified islet fractions were pooled in CMRL 1066 (PAA, Pasching, Austria) supplemented with 10 mM HEPES, $1 \mathrm{mM}$ pyruvate, $1 \mathrm{mM} \mathrm{L-glutamine} \mathrm{(PAA),} \mathrm{10 \%} \mathrm{fetal} \mathrm{calf} \mathrm{serum,} 100 \mathrm{U} / \mathrm{\mu g} / \mathrm{mL}$ penicillin-streptomycin (Gibco, Life Technologies, Paisley, United Kingdom), and $20 \mu \mathrm{g} / \mathrm{mL}$ ciprofloxacin (Bayer, Leverkusen, Germany) for subsequent sampling, aliquotation and preconditioning at $37^{\circ} \mathrm{C}$ in humidified atmosphere $\left(5 \% \mathrm{CO}_{2}\right)$. 
Islet characterisation

Islet yield was evaluated by converting islets to islet equivalents (IEQ) with an average diameter of $150 \mu \mathrm{m}$ (16). After overnight incubation at $37^{\circ} \mathrm{C}$ quantified aliquots of preconditioned or shamtreated islets were washed twice at $1 \mathrm{xg}$ in CMRL 1066 and assessed for secretory capacity. Insulin content and glucose stimulated insulin release during 120 min of static incubation in CMRL 1066 containing either 2.8 or $20 \mathrm{mmol} / \mathrm{L}$ glucose (17) was measured by an enzyme immunoassay specific for human insulin (Mercodia, Uppsala, Sweden). Potential islet damage was determined simultaneously measuring proinsulin release by means of a specific enzyme immunoassay (Mercodia, Uppsala, Sweden). Viability of preconditioned and sham-treated islets was quantified by a fluorometric assay using fluorescein diacetate (Sigma, Dorset, United Kingdom) and propidium iodide (Sigma) for staining of intact and damaged islet cells, respectively (15). Apoptosis in heat-shocked islets was measured by means of fluorescence microscopy (18) utilizing a double labeling with annexin V (Pharmingen, Oxford, United Kingdom) for staining of external phosphatidylserine exposure and propidium iodide for detection of necrotic cells. Early and late apoptosis were distinguished quantifiying the percentage of annexin V-positive and propidium iodide-negative cells and double positive cells, respectively (19).

Islet antiapoptotic preconditioning

Quantified aliquots of 2000 purified IEQ with a purity $\leq 80 \%$ were incubated overnight at $37^{\circ} \mathrm{C}$ in culture medium supplemented with the cell-permeable and irreversible caspase-3 inhibitor AcDEVD-CMK (Calbiochem, Schwalbach, Germany). This inhibitor is specific for caspase-3, and to a minor degree also specific for caspase-6, -7 and -10. To identify the most efficient concentration of this compound, isolated human islets were initially exposed for $80 \mathrm{~min}$ to severe heat shock at $43^{\circ} \mathrm{C}$ prior to overnight recovery at $37^{\circ} \mathrm{C}$ in the presence of Ac-DEVD-CMK added in a range from 0 to $200 \mu \mathrm{mol} / \mathrm{L}$. Afterwards, the expression of activated caspase-3 was detected in heat-shocked islets and visualized by means of a monoclonal rabbit-anti-human antibody (Pharmingen) utilizing Western blot technique and densitometry for quantification as previously described in detail (20). The level of caspase-3 protein expression was calculated as arbitrary units (AU) normalized to microgram sample protein. While preconditioning of transplanted islets was exclusively performed with Ac-DEVD-CMK, glucose-stimulated secretion of insulin and proinsulin was assessed after pretreatment utilizing Ac-DEVD-CMK or benzyloxycarbonyl-DEVD-fluoromethyl ketone (Z-DEVDFMK) (Calbiochem). Sham-treated islets were incubated in culture medium only. 
Diabetes was induced in male, athymic NMRI nude mice or C57/BI6j mice (Harlan, Hanover, Germany) by a single intravenous injection of respectively 240 or $190 \mathrm{mg} / \mathrm{kg}$ streptozotocin (STZ, Sigma, Deisenhofen, Germany) four days prior to transplantation. The nonfasting serum glucose levels of all STZ-treated mice exceeded $350 \mathrm{mg} / \mathrm{dL}$. Islets aliquoted for in vivo studies were exclusively pretreated with Ac-DEVD-CMK (14). After overnight incubation at $37^{\circ} \mathrm{C} 2000$ human IEQ were washed twice at $1 \mathrm{xg}$ and transplanted beneath the kidney capsule of diabetic mice.

Blood samples were taken from the tail vein every other day for determination of postprandial serum glucose utilizing a Beckman glucose analyzer (Beckman Instruments, Fullerton, CA, USA). Nonfasting serum glucose levels $<200 \mathrm{mg} / \mathrm{dL}$ were defined as normoglycemic and considered as graft function. Graft failure was defined by assessment of two subsequent serum glucose levels exceeding $200 \mathrm{mg} / \mathrm{dL}$. Thirty-two days after transplantation nephrectomy of graft-bearing kidneys was performed to demonstrate return of hyperglycemia.

\section{Data analysis}

Analysis of matched samples was carried out by the Friedman test followed by Dunn's test for multiple comparisons utilizing Prism software 6.0b from Graphpad. Comparison of two experimental groups were performed by the Wilcoxon or Mann-Whitney test for pairwise-matched and independent samples, respectively. Graft function calculated as time of normoglycemia was analysed utilizing the Log-rank test. Significance was expressed as P-value and considered for $p<$ 0.05. $P>0.05$ is termed nonsignificant (NS). For clarity, all values are expressed as mean \pm standard error (SEM) rather than the correct non-parametric measures of median and quartiles.

\section{Results}

Effect of Ac-DEVD-CMK on terminal effectors of apoptosis

Exposure of isolated human islets for $80 \mathrm{~min}$ to severe heat shock at $43^{\circ} \mathrm{C}$ increased the expression of stress proteins such as HSP-90 and HSP-70 several-fold by $159 \pm 17$ and $1423 \pm$ $423 \%$, respectively $(p<0.05)$. As exemplarily shown in Fig. 1a, Ac-DEVD-CMK had no effect on the expression of HSP-70, indicating that this caspase inhibitor does not interfere with protein synthesis after sublethal stress. Similar observations were made for HSP-90 (data not shown).

Severe hyperthermic stress resulted in a significant increase of activated caspase-3 expression from $0.041 \pm 0.017 \mathrm{AU} / \mu \mathrm{g}$ protein in sham-treated islets to $0.145 \pm 0.078 \mathrm{AU} / \mu \mathrm{g}$ in heat-exposed islets equivalent to an increase of $300 \pm 39 \%(p<0.05)$. Supplementation with different concentrations of Ac-DEVD-CMK revealed that only a concentration of $200 \mu \mathrm{mol} / \mathrm{L}$ was significantly effective to reduce caspase-3 expression to a baseline level of $0.040 \pm 0.019 \mathrm{AU} / \mathrm{\mu g}$ equivalent to a reduction of $72 \pm 3 \%$ compared to heat-shocked islets not treated with Ac-DEVD- 
CMK (Fig. 1b). For that reason all subsequent transplant and glucose-stimulation experiments were performed using $200 \mu \mathrm{mol} / \mathrm{L}$ Ac-DEVD-CMK.

Exposure of islets to severe hyperthermia increased the percentage of early apoptosis (annexin $\mathrm{V}$ positive, propidium iodide-negative cells) as well as necrosis (annexin V-negative, propidium iodide-positive) from $6.3 \pm 0.3 \%$ and $16.1 \pm 0.4 \%$ in sham-treated islets to $21.2 \pm 1.8 \%(p<0.01)$ and $19.9 \pm 0.6 \%$ (ns) after heat shock, respectively. This is equivalent to an increase of $339 \pm 26 \%$ and $124 \pm 3 \%$, respectively. In consistency with the expression of activated caspase-3, it was found that a significant reduction of external phosphatidylserine exposure to baseline levels could only be obtained using a concentration of $200 \mu \mathrm{mol} / \mathrm{L}$ of Ac-DEVD-CMK (Fig. 2, blank bars). Simultaneously, the administration of Ac-DEVD-CMK gradually increased the proportion of necrosis in heat-shocked islets from $19.9 \pm 0.6 \%$ to $24.9 \pm 0.8 \%(p<0.05)$ (Fig. 2, grey bars). Compared to early apoptosis or necrosis, the proportion of cells undergoing late apoptosis (annexin V-positive, propidium iodide-positive) after heat shock was on a substantially lower level (Fig. 2, black bars). Nevertheless, although the increase of late apoptosis induced by $200 \mu \mathrm{mol} / \mathrm{L}$ of Ac-DEVD-CMK appeared to be marginal it reached statistically relevant significance when compared to $0 \mu \mathrm{mol} / \mathrm{L}(p<0.01)$ and $50 \mu \mathrm{mol} / \mathrm{L}(p<0.05)$ Ac-DEVD-CMK.

\section{Posttransplant islet function}

In contrast to the initial dose-finding study, transplant experiments in diabetic nude mice revealed deterioration of graft function after islet preconditioning with Ac-DEVD-CMK. Transplantation of preconditioned human islets resulted in a significant increase of the nonfasting serum glucose (Fig. 3a). The Log-rank test revealed a significant reduction of graft function by $50 \%$ when comparing the final graft function of $44.4 \%$ in preconditioned islets with $88.9 \%$ determined in sham-treated islets $(p<0.01$, Fig. 3b).

A similar pattern of graft survival was observed after transplantation of preconditioned islets into diabetic immunocompetent mice. Again, islet pretreatment with Ac-DEVD-CMK decreased functional potency of islet grafts resulting in a significant elevation of nonfasting serum glucose as shown in Fig. 4a. While 100\% graft function was measured three days after transplantation of sham-treated islets only $50 \%$ graft survival could be measured at the same time point in mice transplanted with preconditioned islets (Fig. 4b). However, eight days posttransplant none of preconditioned grafts were surviving while $33.3 \%$ of the sham-treated grafts were still functioning (Fig. $4 b, p<0.05$ by Log-rank test). When the experiment was terminated 14 days after transplantion one out of nine sham-treated recipients had a functioning graft.

Islet viability and in vitro function 
The question whether a possible toxicity of Ac-DEVD-CMK as observed after transplantation is related to the chemical structure of the inhibitor or its associated ketone was assessed by viability staining and static glucose stimulation of human islets preconditioned by either Z-DEVD-FMK or Ac-DEVD-CMK $(n=6)$.

A small but nevertheless significant reduction of viability was measured in islets incubated overnight in Ac-DEVD-CMK (77.6 $\pm 2.6 \%, p<0.05)$ in comparison to sham-treated controls (83.9 \pm $0.4 \%)$ and islets pretreated with Z-DEVD-FMK (81.3 $\pm 1.4 \%, N S$ vs. sham-treatment).

The effects of the different caspase inhibitors on insulin secretion were limited except that a significant increase of basal insulin secretion was measured when isolated islets were preconditioned with Z-DEVD-FMK $(p<0.05$, Table 1). No significant effect of preconditioning on glucose stimulation index or intracellular insulin content was observed (Table 1).

The assessment of proinsulin secretion revealed that all caspase inhibitors tested had an impact on islet insulin processing particularly during glucose stimulation. At $20 \mathrm{mmol} / \mathrm{L}$ glucose a higher proinsulin release was found in all preconditioned islets compared to sham-treated islets reaching statistical significance only after pretreatment with Ac-DEVD-CMK ( $p<0.05$ vs. sham-treated, Table 2). This resulted in a significantly higher proinsulin stimulation index in Ac-DEVD-CMKpreconditioned islets compared to sham-treated controls and Z-DEVD-FMK pretreated islets $(p<$ 0.05 , Table 2). In comparison to sham-treated controls, that were characterised by a significantly increased insulin-to-proinsulin ratio at $20 \mathrm{mmol} / \mathrm{L}$ glucose ( $p<0.05 \mathrm{vs}$. basal, Table 2 ), the insulinto-proinsulin ratio of Z-DEVD-FMK pretreated islets remained unchanged after switching from basal to high glucose concentration or decreased significantly in Ac-DEVD-CMK preconditioned islets ( $p<0.05$ vs. basal, Table 2$)$.

\section{Discussion}

The number of adverse factors affecting islet integrity during pancreas processing performed for islet isolation and transplantation is substantial. The process of organ procurement is usually initiated after confirmation of brain death which induces a cascade of proinflammatory events in the pancreas and other peripheral organs $(21,22)$. The massive release of cytokines after brain death can simultaneously induce necrosis and apoptosis resulting in a substantial loss of islet morphological and functional integrity $(23,24)$. Prolonged cold ischemia is another variable that is associated with a reduction of islet viability $(6,25)$. It was demonstrated that the detrimental effects of brain death are aggrevated when retrieved tissue is exposed to prolonged periods of cold ischemia (26). This includes also the expression of proapoptotic key molecules such as Bax and caspases $(27,28)$. When islet isolation is performed, the enzymatic digestion of the pancreas results in the disconnection of islets from vasculature and the destruction of the extracellular matrix $(29,30)$. The disruption of vital cell-matrix interactions results in the activation of proapoptotic pathways $(31,32)$. During enzymatic pancreas dissociation, usually performed at $37^{\circ} \mathrm{C}$, islets are 
exposed to an anoxic milieu which can be regarded as warm ischemia thus rapidly depleting ATP and potentiating cellular death pathways (33). At the end of the isolation procedure, purified human islets are characterized by the overexpression of proapoptotic mediators $(28,34,35)$ which may further increase during pretransplant free-floating culture $(8,36)$.

The caspase cascade seems to be the rate limiting step for apoptosis (37). Pretreatment of freshly isolated islets with caspase inhibitors appears as a reasonable option to optimize islet graft function after transplantation as proven in human islets preconditioned by means of the broad spectrum caspase inhibitor N-benzyloxycabonyl-Val-Asp-FMK (Z-VD-FMK) and successfully grafted in diabetic nude mice (38). Nevertheless, as anti-caspase treatment was continued in the recipients it is difficult to compare this study with the present one. Another approach, similar to the present one, demonstrated that diabetic nude mice can successfully be cured by human islets treated for two days of culture with the caspase-3 inhibitor Z-DEVD-FMK prior to transplantation (39). In contrast, a reduction in posttransplant islet function was noted by pretreating porcine islets with the caspase-3 inhibitor Ac-DEVD-CMK prior to transplantation into immunodeficient or immunocompetent diabetic mice (40). The finding of the present study that islet preconditioning with Ac-DEVD-CMK increases proinsulin release may provide an explanation for our results previously obtained in pretreated pig islets. The exact mechanism behind this phenomenon remains to be clarified but the increase of necrotic cell death that we measured in preconditioned human islets confirm previous experiments in canine and human islets revealing that treatment with caspase- 3 inhibitors can cause a shift from apoptotic to necrotic cell death (41). This transformation is associated with mitochondrial dysfunction, increased formation of radical oxygen species and depletion of ATP due to increased activation of PARP, the main substrate of caspase3 (42).

In agreement with the present study, it was previously demonstrated that an increased glucosestimulated proinsulin release predicts human islet dysfunction after transplantation into diabetic nude mice (43). Remarkably, the magnitude of proinsulin measured after glucose challenge in our experiments reached nearly the same level that had been observed after acute islet damage caused by the instant blood mediated immune reaction (44). This finding suggests an acute toxicity of Ac-DEVD-CMK. However, the reduction of the insulin-to-proinsulin ratio during acute glucose challenge reached significance after treatment with Ac-DEVD-CMK but not with Z-DEVD-FMK which may partially explain the discrepancy between our study and the report of Nakano et al. (39). So far, we can only speculate whether the interference of Ac-DEVD-CMK with proinsulin conversion is related to its associated chloromethyl-ketone CMK as indicated by experiments in Balb/c mice treated with another CMK-linked protease inhibitor, N-alpha-tosyl-L-lysyl-chloromethylketone. This compound exerted acute toxicity when mice were treated with a single injection of 59 $\mathrm{mg} / \mathrm{kg}$ which is equivalent to a theoretic concentration ranging from 40 to $67 \mu \mathrm{mol} / \mathrm{L} \mathrm{CMK} \mathrm{(45).} \mathrm{The}$ proportion of CMK that was used in the present study corresponds to a concentration of $34 \mu \mathrm{mol} / \mathrm{L}$ which is within the upper range for chronic effects. The CMK-related toxicity can be partially 
explained by its glutathione-depleting effect found in different tissues (46). This may be of particular importance for islets which are characterized by a specifically low radical-scavenging capacity $(47,48)$ simultaneously suffering from proinflammatory conditions as a consequence of effective caspase-3 inhibition (42).

Based on the present findings we conclude that human islet antiapoptotic preconditioning utilizing Ac-DEVD-CMK reduces the metabolic potency of pretreated islets to cure diabetic mice. The deterioration of graft function is associated with reduced viability and enhanced release of proinsulin as confirmed by glucose stimulation in vitro. The mechanisms behind this phenomenon are not fully understood but appeared to be partially related to the associated chloromethyl-ketone CMK. Nevertheless, further studies are required to clarify the proinflammatory effects of Ac-DEVDCMK and to identify biocompatible caspase inhibitors suitable for islet preconditioning.

\section{References}

1. Shapiro AM, Ricordi C, Hering BJ, et al. (2006) International trial of the Edmonton protocol for islet transplantation. N Engl J Med 355:1318-1330.

2. Vantyghem MC, Kerr-Conte J, Arnalsteen L, et al. (2009) Primary graft function, metabolic control, and graft survival after islet transplantation. Diabetes Care 32:1473-1478.

3. Bellin MD, Kandaswamy R, Parkey J, et al. (2008) Prolonged insulin independence after islet allotransplants in recipients with type 1 diabetes. Am J Transplant 8:2463-2470.

4. Guignard AP, Oberholzer J, Benhamou PY, et al. (2004) Cost analysis of human islet transplantation for the treatment of type 1 diabetes in the Swiss-French Consortium GRAGIL. Diabetes Care 27:895-900.

5. Kempf MC, Andres A, Morel P, et al. (2005) Logistics and transplant coordination activity in the GRAGIL Swiss-French multicenter network of islet transplantation. Transplantation 79:1200-1205.

6. Caballero-Corbalan J, Brandhorst $\mathrm{H}$, Malm H, et al. (2012) Using HTK for prolonged pancreas preservation prior to human islet isolation. J Surg Res 175:163-168.

7. Johansson H, Lukinius A, Moberg L, et al. (2005) Tissue factor produced by the endocrine cells of the islets of langerhans is associated with a negative outcome of clinical islet transplantation. Diabetes 54:17551762.

8. Thomas FT, Contreras JL, Bilbao G, Ricordi C, Curiel D, Thomas JM. (1999) Anoikis, extracellular matrix, and apoptosis factors in isolated cell transplantation. Surgery 126:299-304.

9. Puthalakath $\mathrm{H}$, Villunger $\mathrm{A}$, O'Reilly LA, et al. (2001) Bmf: a proapoptotic BH3-only protein regulated by interaction with the myosin $V$ actin motor complex, activated by anoikis. Science 293:1829-1832.

10. Larsen CM, Wadt KA, Juhl LF, et al. (1998) Interleukin-1beta-induced rat pancreatic islet nitric oxide synthesis requires both the p38 and extracellular signal-regulated kinase 1/2 mitogen-activated protein kinases. J Biol Chem 273:15294-15300.

11. Schliess F, Haussinger D. (2002) The cellular hydration state: a critical determinant for cell death and survival. Biol Chem 383:577-583.

12. Daoud JT, Petropavlovskaia MS, Patapas JM, et al. (2011) Long-term in vitro human pancreatic islet culture using three-dimensional microfabricated scaffolds. Biomaterials 32:1536-1542. 
13. Moritz W, Meier F, Stroka DM, et al. (2002) Apoptosis in hypoxic human pancreatic islets correlates with HIF-1alpha expression. FASEB J 16:745-747.

14. Brandhorst H, Brandhorst D, Kumarasamy V, Maataoui A, Brendel MD, Bretzel RG. (2003) Pretreatment of isolated islets with caspase-3 inhibitor DEVD increases graft survival after xenotransplantation. Transplant Proc 35:2142.

15. Brandhorst H, Brandhorst D, Brendel MD, Hering BJ, Bretzel RG. (1998) Assessment of intracellular insulin content during all steps of human islet isolation procedure. Cell Transplant 7:489-495.

16. Ricordi C, Gray DW, Hering BJ, et al. (1990) Islet isolation assessment in man and large animals. Acta Diabetol Lat 27:185-195.

17. Brandhorst H, Olbrich M, Neumann A, Jahr H, Brandhorst D. (2007) Effect of pretransplant preconditioning by whole body hyperthermia on islet graft survival. Cell Transplant 16:707-715.

18. Ris F, Hammar E, Bosco D, et al. (2002) Impact of integrin-matrix matching and inhibition of apoptosis on the survival of purified human beta-cells in vitro. Diabetologia 45:841-850.

19. Berney T, Molano RD, Cattan P, et al. (2001) Endotoxin-mediated delayed islet graft function is associated with increased intra-islet cytokine production and islet cell apoptosis. Transplantation 71:125-132. 20. Brandhorst D, Brandhorst H, Kumarasamy V, et al. (2003) Hyperthermic preconditioning protects pig islet grafts from early inflammation but enhances rejection in immunocompetent mice. Cell Transplant 12:859-865.

21. Takada M, Nadeau KC, Hancock WW, et al. (1998) Effects of explosive brain death on cytokine activation of peripheral organs in the rat. Transplantation 65:1533-1542.

22. Skrabal CA, Thompson LO, Potapov EV, et al. (2005) Organ-specific regulation of pro-inflammatory molecules in heart, lung, and kidney following brain death. J Surg Res 123:118-125.

23. Contreras JL, Eckstein C, Smyth CA, et al. (2003) Brain death significantly reduces isolated pancreatic islet yields and functionality in vitro and in vivo after transplantation in rats. Diabetes 52:2935-2942.

24. Saldeen J. (2000) Cytokines induce both necrosis and apoptosis via a common Bcl-2-inhibitable pathway in rat insulin-producing cells. Endocrinology 141:2003-2010.

25. Lakey JR, Rajotte RV, Warnock GL, Kneteman NM. (1995) Human pancreas preservation prior to islet isolation. Cold ischemic tolerance. Transplantation 59:689-694.

26. Hoeger S, Petrov K, Reisenbuechler A, et al. (2009) The additional detrimental effects of cold preservation on transplantation-associated injury in kidneys from living and brain-dead donor rats. Transplantation 87:52-58.

27. Matsuda T, Suzuki Y, Tanioka Y, et al. (2003) Pancreas preservation by the 2-layer cold storage method before islet isolation protects isolated islets against apoptosis through the mitochondrial pathway. Surgery 134:437-445.

28. Thomas D, Yang H, Boffa DJ, et al. (2002) Proapoptotic Bax is hyperexpressed in isolated human islets compared with antiapoptotic Bcl-2. Transplantation 74:1489-1496.

29. Wang RN, Paraskevas S, Rosenberg L. (1999) Characterization of integrin expression in islets isolated from hamster, canine, porcine, and human pancreas. J Histochem Cytochem 47:499-506.

30. Stendahl JC, Kaufman DB, Stupp SI. (2009) Extracellular matrix in pancreatic islets: relevance to scaffold design and transplantation. Cell Transplant 18:1-12.

31. Rosenberg L, Wang R, Paraskevas S, Maysinger D. (1999) Structural and functional changes resulting from islet isolation lead to islet cell death. Surgery 126:393-398. 
32. Krishnamurthy M, Li J, Fellows GF, Rosenberg L, Goodyer CG, Wang R. (2011) Integrin \{alpha\}3, but not beta\}1, regulates islet cell survival and function via PI3K/Akt signaling pathways. Endocrinology 152:424-435.

33. Goto T, Tanioka Y, Sakai T, et al. (2007) Application of the two-layer method on pancreas digestion results in improved islet yield and maintained viability of isolated islets. Transplantation 83:754-758.

34. Campbell PD, Weinberg A, Chee J, et al. (2012) Expression of pro- and antiapoptotic molecules of the bcl-2 family in human islets postisolation. Cell Transplant 21:49-60.

35. Abdelli S, Ansite J, Roduit R, et al. (2004) Intracellular stress signaling pathways activated during human islet preparation and following acute cytokine exposure. Diabetes 53:2815-2823.

36. Lucas-Clerc C, Massart C, Campion JP, Launois B, Nicol M. (1993) Long-term culture of human pancreatic islets in an extracellular matrix: morphological and metabolic effects. Mol Cell Endocrinol 94:9-20.

37. McConkey DJ. (1998) Biochemical determinants of apoptosis and necrosis. Toxicol Lett 99:157-168.

38. Emamaullee JA, Davis J, Pawlick R, et al. (2008) The caspase selective inhibitor EP1013 augments human islet graft function and longevity in marginal mass islet transplantation in mice. Diabetes 57:15561566.

39. Nakano M, Matsumoto I, Sawada T, et al. (2004) Caspase-3 inhibitor prevents apoptosis of human islets immediately after isolation and improves islet graft function. Pancreas 29:104-109.

40. Brandhorst D, Kumarasamy V, Maatoui A, Alt A, Bretzel RG, Brandhorst H. (2006) Porcine islet graft function is affected by pretreatment with a caspase-3 inhibitor. Cell Transplant 15:311-317.

41. Aikin R, Rosenberg L, Paraskevas S, Maysinger D. (2004) Inhibition of caspase-mediated PARP-1 cleavage results in increased necrosis in isolated islets of Langerhans. J Mol Med 82:389-397.

42. Prabhakaran K, Li L, Borowitz JL, Isom GE. (2004) Caspase inhibition switches the mode of cell death induced by cyanide by enhancing reactive oxygen species generation and PARP-1 activation. Toxicol Appl Pharmacol 195:194-202.

43. Piemonti L, Bertuzzi F, Nano R, et al. (1999) Effects of cryopreservation on in vitro and in vivo long-term function of human islets. Transplantation 68:655-662.

44. Titus TT, Horton PJ, Badet L, et al. (2003) Adverse outcome of human islet-allogeneic blood interaction. Transplantation 75:1317-1322.

45. Litterst CL. (1980) Acute and subchronic toxicity of the protease inhibitor N-alpha-tosyl-L-lysylchloromethylketone (TLCK) in mice. Drug Chem Toxicol 3:227-235.

46. Smith HJ. (1978) Perspectives in the design of small molecule enzyme inhibitors as useful drugs. J Theor Biol 73:531-538.

47. Lenzen S, Drinkgern J, Tiedge M. (1996) Low antioxidant enzyme gene expression in pancreatic islets compared with various other mouse tissues. Free Radic Biol Med 20:463-466.

48. Tiedge M, Lortz S, Drinkgern J, Lenzen S. (1997) Relation between antioxidant enzyme gene expression and antioxidative defense status of insulin-producing cells. Diabetes 46:1733-1742.

\section{Tables}

Table 1 Effect of DEVD-based caspase-3 Inhibitors on glucose-stimulated insulin release and intracellular insulin content 


\begin{tabular}{|c|c|c|c|c|c|}
\hline & \multicolumn{2}{|c|}{$\begin{array}{c}\text { Insulin Release } \\
\text { (pmol/IEQ/120 min) }\end{array}$} & \multirow[b]{2}{*}{$\begin{array}{l}\text { Stimulation } \\
\text { Index }\end{array}$} & \multirow[b]{2}{*}{$\begin{array}{l}\text { Insulin Content } \\
\text { (pmol/IEQ) }\end{array}$} & \\
\hline & $\begin{array}{l}2.8 \mathrm{mM} \\
\text { Glucose }\end{array}$ & $\begin{array}{l}20 \mathrm{mM} \\
\text { Glucose }\end{array}$ & & & \\
\hline Sham-treated & $0.056 \pm 0.012$ & $0.185 \pm 0.028^{a}$ & $3.83 \pm 0.79$ & $2.07 \pm 0.46$ & \\
\hline Z-DEVD-FMK & $0.114 \pm 0.026^{b}$ & $0.267 \pm 0.034^{a}$ & $2.71 \pm 0.43$ & $1.47 \pm 0.40$ & \\
\hline Ac-DEVD-CMK & $0.081 \pm 0.018$ & $0.196 \pm 0.035^{a}$ & $2.69 \pm 0.26$ & $1.83 \pm 0.42$ & \\
\hline \multicolumn{6}{|c|}{$\begin{array}{l}{ }^{\mathrm{a}} p<0.05 \text { vs. basal insulin release (Wilcoxon test); }{ }^{\mathrm{b}} p<0 \\
\text { expressed as means } \pm \text { SEM of six individual experiments. }\end{array}$} \\
\hline & \multicolumn{2}{|c|}{$\begin{array}{l}\text { Proinsulin Release } \\
\text { (pmol/IEQ/120 min) }\end{array}$} & & \multicolumn{2}{|c|}{$\begin{array}{l}\text { Insulin/Proinsulin } \\
\text { Ratio }\end{array}$} \\
\hline & $2.8 \mathrm{mM}$ & $20 \mathrm{mM}$ & Stimulation & $2.8 \mathrm{mM}$ & $20 \mathrm{mM}$ \\
\hline & Glucose & Glucose & Index & Glucose & Glucose \\
\hline Sham-treated & $0.0023 \pm 0.0002$ & $0.0039 \pm 0.0004^{a}$ & $1.74 \pm 0.15^{c}$ & $27.4 \pm 9.1$ & $48.5 \pm 8.8^{\mathrm{a}, \mathrm{c}}$ \\
\hline Z-DEVD-FMK & $0.0045 \pm 0.0012$ & $0.0122 \pm 0.0052^{\mathrm{a}}$ & $2.47 \pm 0.41^{c}$ & $29.5 \pm 6.2$ & $36.6 \pm 8.3$ \\
\hline Ac-DEVD-CMK & $0.0028 \pm 0.0004$ & $0.0131 \pm 0.0021^{a, b}$ & $4.58 \pm 0.41$ & $30.5 \pm 8.6$ & $15.4 \pm 2.8^{a}$ \\
\hline
\end{tabular}

${ }^{\mathrm{a}} p<0.05$ vs. basal release (Wilcoxon test); ${ }^{b} p<0.05$ vs. sham-treated controls; ${ }^{c} p<0.05$ vs. AcDEVD-CMK.

Data are expressed as means \pm SEM of six individual experiments.

Figure legends 

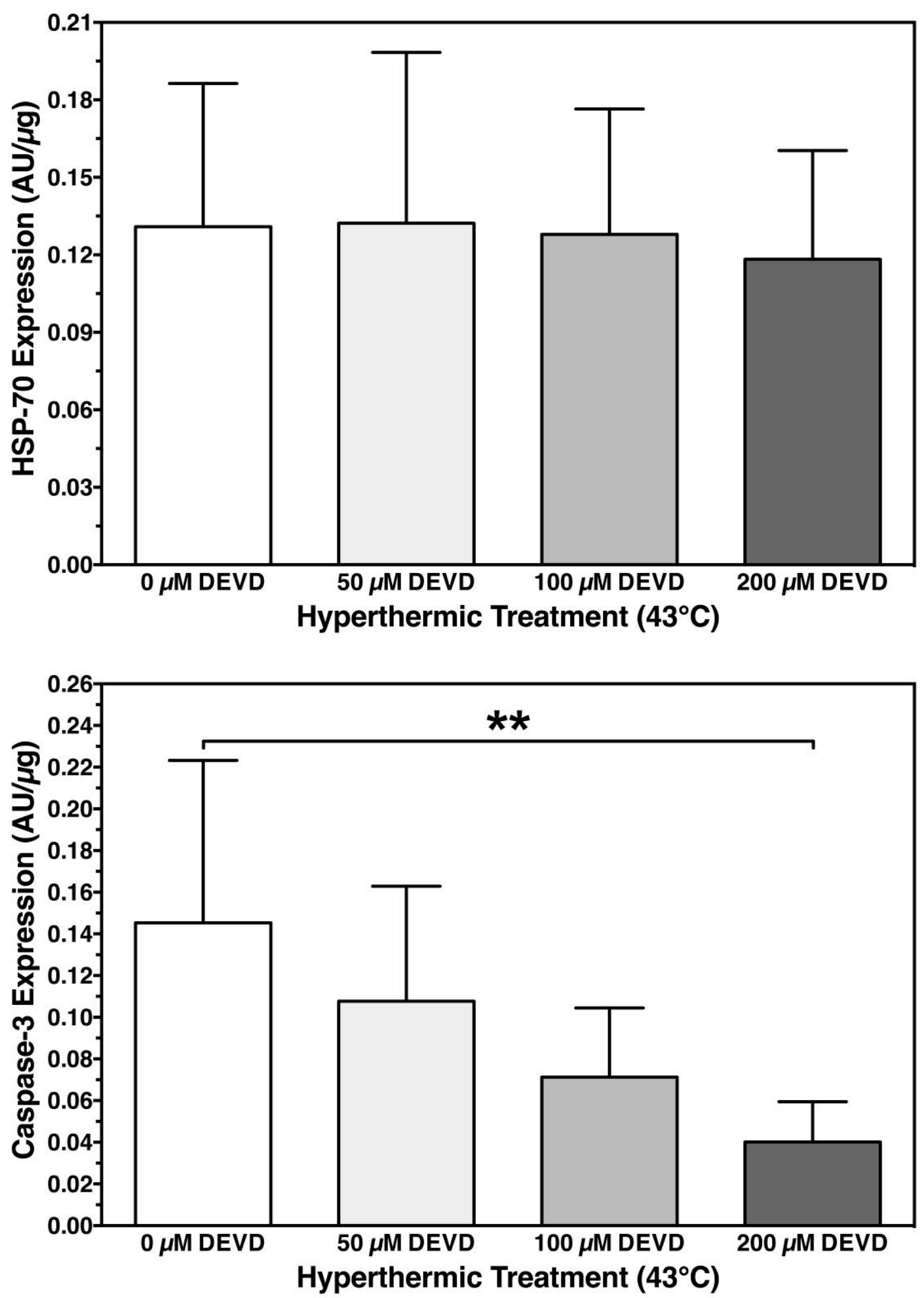

Fig. 1 Protein expression of (a) HSP-70 and (b) activated caspase-3 in isolated human islets exposed for $80 \mathrm{~min}$ to severe heat shock at $43^{\circ} \mathrm{C}$ prior to overnight recovery at $37^{\circ} \mathrm{C}$ in the presence of different concentrations of Ac-DEVD-CMK. Statistical analysis revealed ${ }^{* *} p<0.01$ comparing caspase-3 protein expression at $0 \mu \mathrm{mol} / \mathrm{L}$ and $200 \mu \mathrm{mol} / \mathrm{L}$ Ac-DEVD-CMK as indicated in (b). Data are expressed as means \pm SEM of islet isolations from five different donors. 


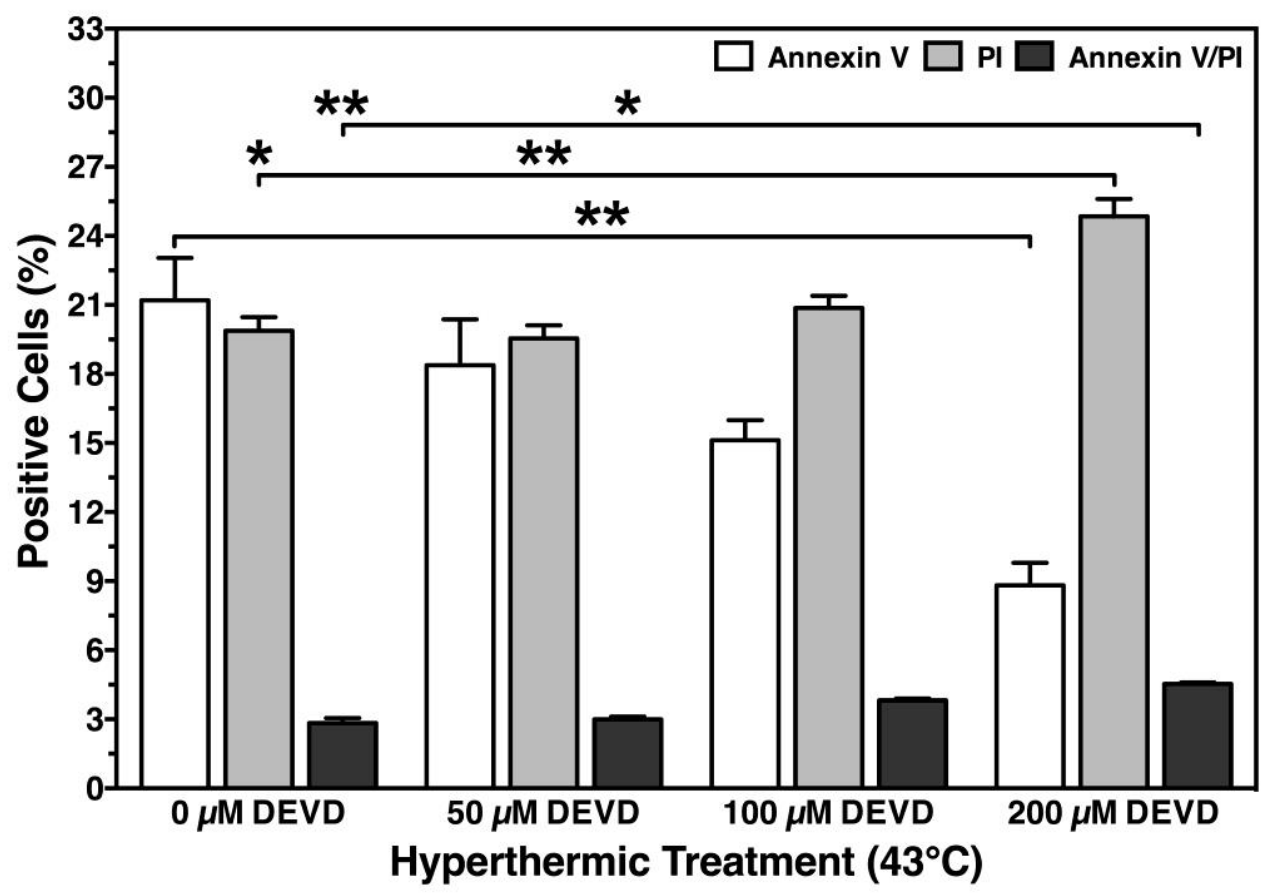

Fig. 2 Percentage of annexin V-positive (blank bars), propidium iodide-positive (grey bars) and double positive (black bars) cells representing respectively early apoptotic, necrotic and late apoptotic cells in isolated human islets exposed for $80 \mathrm{~min}$ to severe heat shock at $43^{\circ} \mathrm{C}$ prior to overnight recovery at $37^{\circ} \mathrm{C}$ in the presence of different concentrations of Ac-DEVD-CMK. Statistical analysis revealed ${ }^{*} p<0.05$ and ${ }^{* *} p<0.01$ comparing proportion of early apoptotic, necrotic or late apoptotic cells after treatment with $0 \mu \mathrm{mol} / \mathrm{L}$ and $50 \mu \mathrm{mol} / \mathrm{L}$ versus $200 \mu \mathrm{mol} / \mathrm{L}$ AcDEVD-CMK. Data are expressed as means \pm SEM of islet isolations from six different donors.

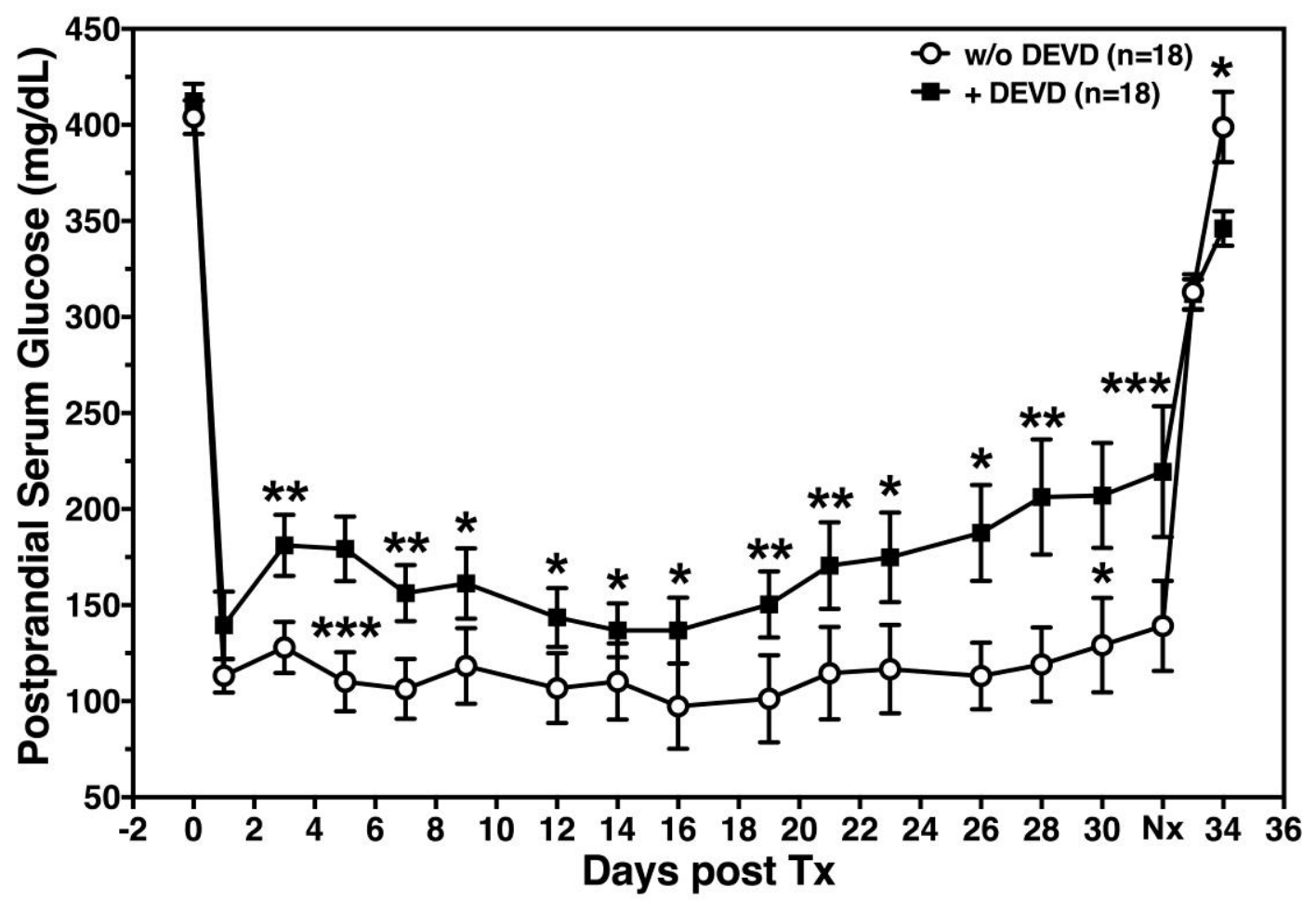




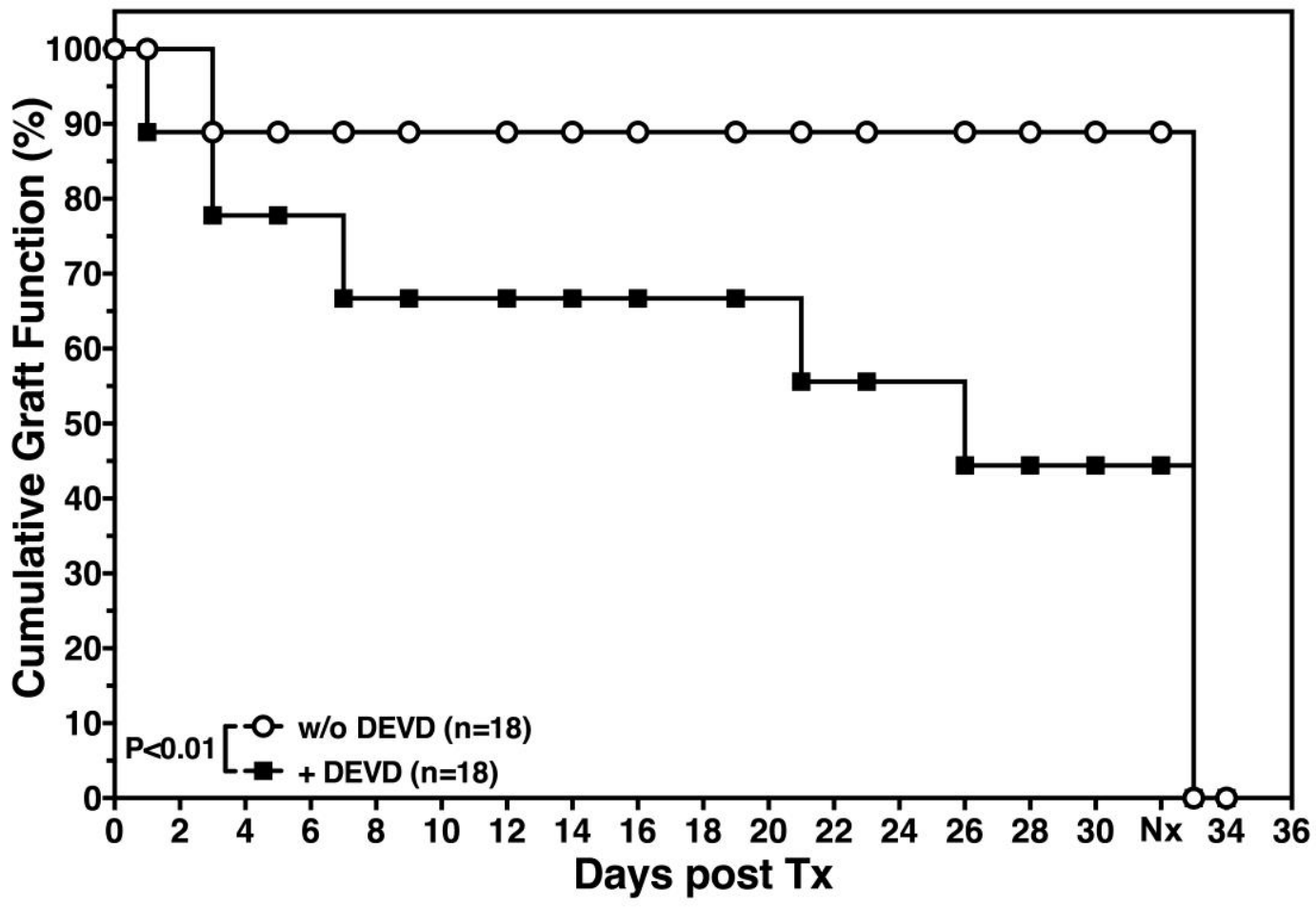

Fig. 3 Postprandial serum glucose levels (a) and cumulative graft function (b) of sham-treated (blank circles) or Ac-DEVD-CMK-pretreated (black squares) human islets transplanted beneath the kidney capsule of diabetic NMRI nude mice. Graft nephrectomy (Nx) was performed 32 days post transplantation. Statistical analysis by Mann-Whitney test revealed ${ }^{* *} p<0.001,{ }^{* *} p<0.01$ and ${ }^{*} p$ $<0.05$ comparing serum glucose levels by day. Data are expressed as means \pm SEM of islet isolations from four different donors (a). Analysis of cumulative graft function by Log-rank test revealed $p<0.01$ as indicated in (b).

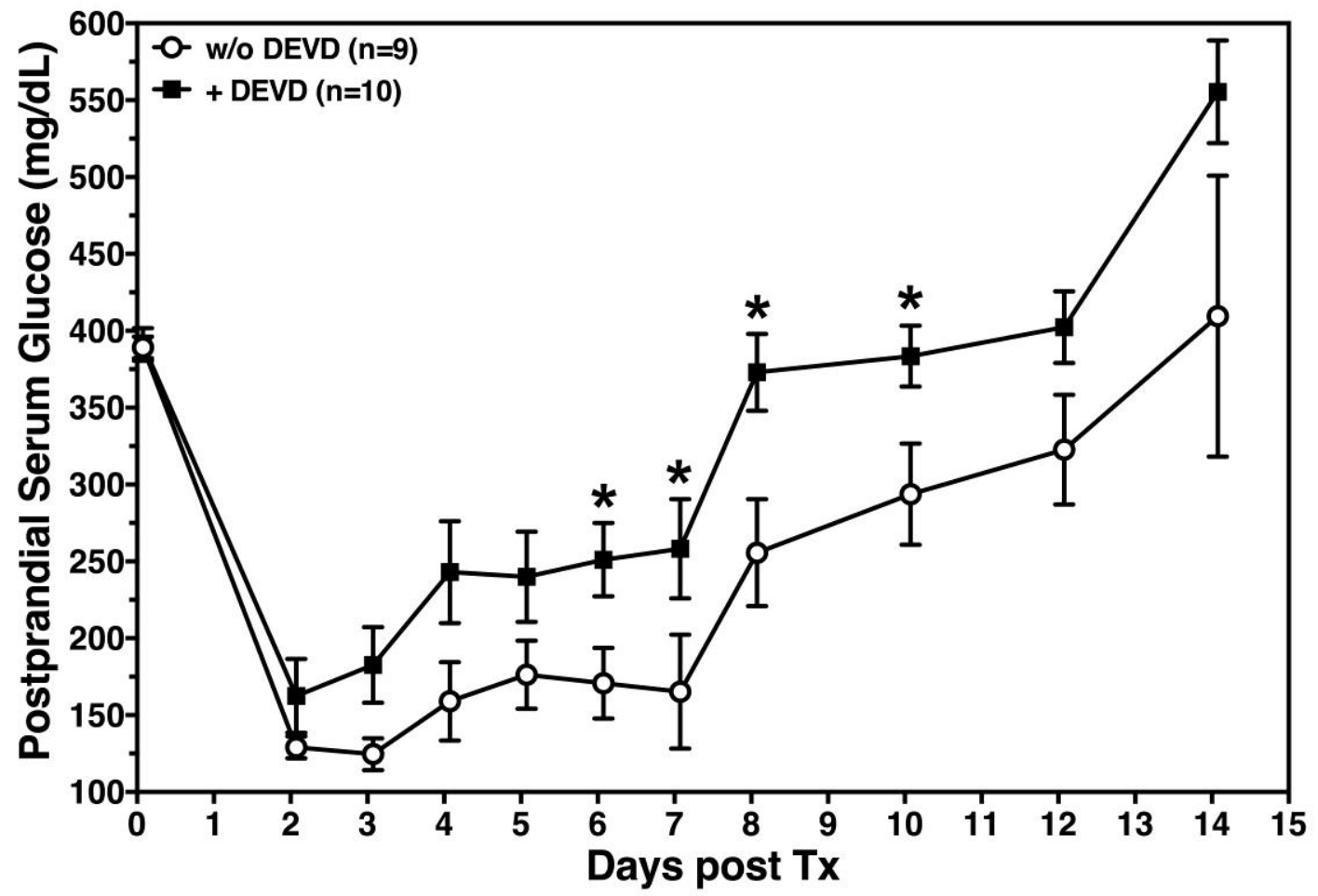




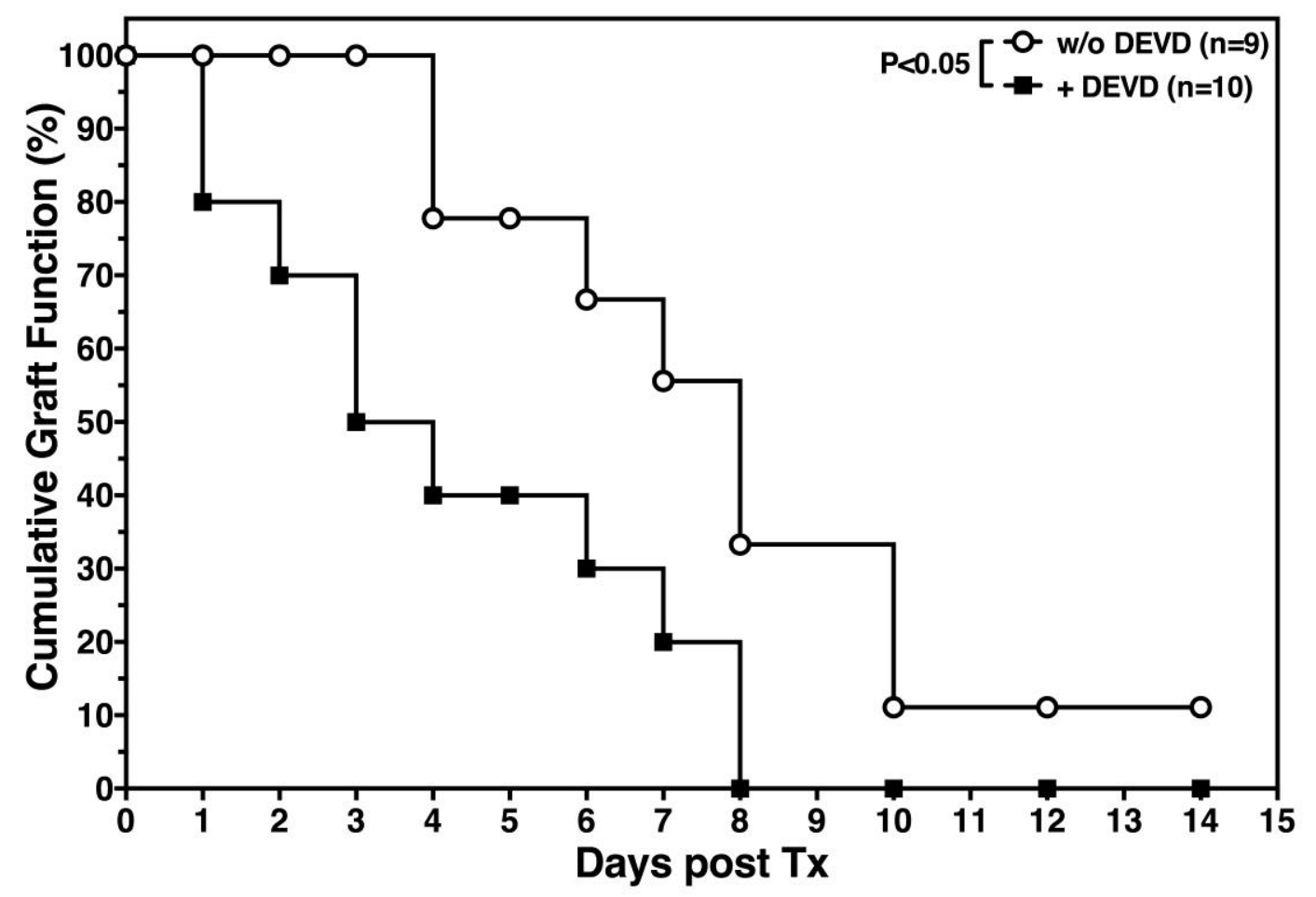

Fig. 4 Postprandial serum glucose levels (a) and cumulative graft function (b) of sham-treated (blank circles) or Ac-DEVD-CMK-pretreated (black squares) human islets transplanted beneath the kidney capsule of diabetic C57/BI6j mice. Statistical analysis by Mann-Whitney test revealed * $p<$ 0.05 comparing serum glucose levels by day. Data are expressed as means \pm SEM of islet isolations from three different donors (a). Analysis of cumulative graft function by Log-rank test revealed $p<0.05$ as indicated in (b). 